\title{
Comparison of satellite limb-sounding humidity climatologies of the uppermost tropical troposphere
}

\author{
M. Ekström ${ }^{1}$, P. Eriksson ${ }^{1}$, W. G. Read $^{2}$, M. Milz ${ }^{3,}$, and D. P. Murtagh ${ }^{1}$ \\ ${ }^{1}$ Department of Radio and Space Science, Chalmers University of Technology, Gothenburg, Sweden \\ ${ }^{2}$ Jet Propulsion Laboratory, California Institute of Technology, Pasadena, California, USA \\ ${ }^{3}$ Department of Space Science, Luleå Technical University, Kiruna, Sweden \\ * formerly at: Institut für Meteorologie und Klimaforschung, Universität Karlsruhe (TH)/Forschungszentrum Karlsruhe, \\ Karlsruhe, Germany
}

Received: 17 July 2007 - Published in Atmos. Chem. Phys. Discuss.: 28 August 2007

Revised: 22 November 2007 - Accepted: 19 December 2007 - Published: 25 January 2008

\begin{abstract}
Humidity climatologies of the tropical uppermost troposphere from satellite limb emission measurements have been compared. Four instruments are considered; UARS-MLS, Odin-SMR, and Aura-MLS operating in the microwave region, and MIPAS in the infrared region. A reference for the comparison is obtained by MOZAIC in-situ measurements.

The upper tropospheric humidity products were compared on basis of their empirical probability density functions and seasonally averaged horizontal fields at two altitude layers, 12 and $15 \mathrm{~km}$. The probability density functions of the microwave datasets were found to be in very good agreement with each other, and were also consistent with MOZAIC. The average seasonal humidities differ with less than $10 \%$ RHi between the instruments, indicating that stated measurement accuracies of $20-30 \%$ are conservative estimates. The systematic uncertainty in Odin-SMR data due to cloud correction was also independently estimated to be $10 \%$ RHi. MIPAS humidity profiles were found to suffer from cloud contamination, with only $30 \%$ of the measurements reaching into the upper troposphere, but under clear-sky conditions there is a good agreement between MIPAS, Odin-SMR and Aura-MLS.

Odin-SMR and the two MLS datasets can be treated as independent, being based on different underlying spectroscopy and technology. The good agreement between the microwave limb-sounders, and MOZAIC, is therefore an important step towards understanding the upper tropospheric humidity. The found accuracy of $10 \%$ RHi is approaching the level required to validate climate modelling of the upper troposphere hu-
\end{abstract}

Correspondence to: M. Ekström

(mattias.ekstrom@chalmers.se) midity. The comparison of microwave and infrared also stresses that microwave limb-sounding is necessary for a complete view of the upper troposphere.

\section{Introduction}

Water in the troposphere plays an important part in determining the radiative and dynamic properties of the Earth's atmosphere. Due to its broad absorption features in the infrared (IR), water vapour is the dominant green-house gas. To put it in context, the humidity needs to be known with an accuracy better than $10 \%$ in order not to introduce radiative effects comparable to a doubling of $\mathrm{CO}_{2}$ (Harries, 1997). To achieve this in the upper troposphere has proven difficult for both in-situ and remote techniques (Soden et al., 2004). One challenge is to correctly capture the strong gradients that appear in the humidity field on a multitude of spatial- and temporal scales. The upper tropical troposphere is supplied with water vapour by deep convective systems that have their largest outflow around $200 \mathrm{hPa}$. These systems are also important in the formation of cirrus clouds and in the transport and dehydration of air that takes part in the troposphere-stratosphere exchange. The relative contribution of mechanisms that contribute to this exchange is yet an unresolved question (Sherwood and Dessler, 2000). Together these effects; the radiative effect, the formation of clouds and the troposphere-stratosphere exchange, make the humidity in the upper troposphere an important component in accurate climate modelling. However, the global and seasonal distributions of water vapour in the upper troposphere/lower stratosphere (UT/LS) region are not known with sufficient

Published by Copernicus Publications on behalf of the European Geosciences Union. 
accuracy to validate the existing climate models (Kley et al., 2000).

Global coverage can be obtained through satellite measurements, but there are two major challenges to these measurements in the UT. These observations are required to have high vertical resolution, as structures in temperature and humidity on fine vertical scales are very important. Furthermore, the high occurrence of clouds in the tropical regions also requires that the measurements are cloud independent. Satellite measurements of upper tropospheric humidity (UTH) with high accuracy are therefore difficult to achieve. Clouds restrict visible/IR observations to downlooking geometries, resulting in low vertical resolution and measurements with sensitivity to the lower/middle troposphere. Microwave observations on the other hand can be performed in limb-sounding, which gives relatively cloud insensitive observations with better vertical resolution than nadir-sounding.

Limb emission measurements of water vapour started in the late 1970s with the LRIR and LIMS instruments on board Nimbus 6 and 7 (Gille et al., 1980). These first experimental measurements were only operated for short periods, and did not produce any results for the upper troposphere. A decade later two microwave limb-sounding instruments were launched, the MLS instrument on board UARS (Barath et al., 1993) and MAS on board the space shuttle (Croskey et al., 1992). Of these instruments, only UARS-MLS has provided humidity measurements of good quality in the upper tropical troposphere. In recent years, as the role played by UTH in the Earth's climate has become more evident, observations of UTH have been included in the scientific objectives of several atmospheric satellite missions. In this paper, the UTH measurements from UARS-MLS and three more recent instruments are studied. These instruments are; Odin-SMR operating in the sub-millimeter region (Nordh et al., 2003), MIPAS in the IR region (Fischer and Oelhaf, 1996) and most recently Aura-MLS (Waters et al., 2006).

The paper is organized as follows. First the individual instruments and their datasets are presented along with considerations for data usage and a brief description of how cloud influence is handled (Sect. 2). Considerations for compiling the climatologies are discussed (Sect. 3.1) before they are compared on the basis of their probability density functions (Sect. 3.2) and seasonal averages (Sect. 3.3). Finally, some conclusions from the comparisons are presented and the general agreement of the different climatologies are discussed (Sect. 4).

\section{Data}

This section describes the different datasets that are included in this study. Focus lies on observation and retrieval aspects important for UTH measurements, of which cloud handling is potentially one of the most important factors. The involved datasets are Odin-SMR, UARS-MLS, Aura-MLS, MIPAS and MOZAIC.

\subsection{Odin-SMR}

Odin was launched in February 2001. It has now exceeded its designed lifetime of two years by a factor of three and is still operational. On board it carries the first sub-millimeter radiometer to observe the atmosphere from space, Odin-SMR (Frisk et al., 2003). Observations are performed in the frequency range $480-540 \mathrm{GHz}$ and its primary atmospheric objectives are focused on stratospheric/mesospheric observations (Murtagh et al., 2002). The stratospheric observations used for the UTH retrieval are performed on average every third day.

\subsubsection{Data treatment}

Relative humidity with respect to ice (RHi) in the UT is retrieved by an offline method using only the lowest tangent altitudes $(<9 \mathrm{~km})$. The method together with thorough characterization and error analysis is described by Ekström et al. (2007). The retrieval is based on observations in two frequency bands, $501 \mathrm{GHz}$ and $544 \mathrm{GHz}$. At the lowest tangent altitudes these bands are optically thick and the intensity depends only on temperature, humidity and possible cloud influence. Spectra are inverted individually using temperature profiles from ECMWF, but instead of a vertical profile this yields information at two vertically separated layers in the UT. The sounding altitude of a measurement is humidity dependent, for drier conditions the observation reaches deeper into the atmosphere. The altitude is determined from the optical depth of simulated clear-sky radiances using the inverted RHi. The $501 \mathrm{GHz}$ band sounds altitudes around the $205 \mathrm{hPa}$ pressure level and the $544 \mathrm{GHz}$ band around $127 \mathrm{hPa}$ (Fig. 1).

Observations of the UT during the time period 2001-2006 have been used. The main error source is the random calibration uncertainty, which results in poor precision for single observations (10-60\%). The systematic calibration uncertainty is on the other hand low and the total systematic uncertainty, including temperature and spectroscopic parameters, correspond to a relative retrieval error of $10 \%$ (Ekström et al., 2007). It is recommended to average the data, so that the random uncertainty component can be reduced, leaving the low systematic error to dominate the accuracy. From the relative humidity weighting functions (Ekström et al., 2007, Fig. 2), the vertical resolution of individual measurements is estimated to $3-4 \mathrm{~km}$.

The $544 \mathrm{GHz}$ band has a larger random error component compared to the $501 \mathrm{GHz}$ band and only observations with sufficient integration time $(1.85 \mathrm{~s})$ are included. Such observations are performed less frequently and as a consequence, the dataset for the upper level is much sparser than for the lower. 


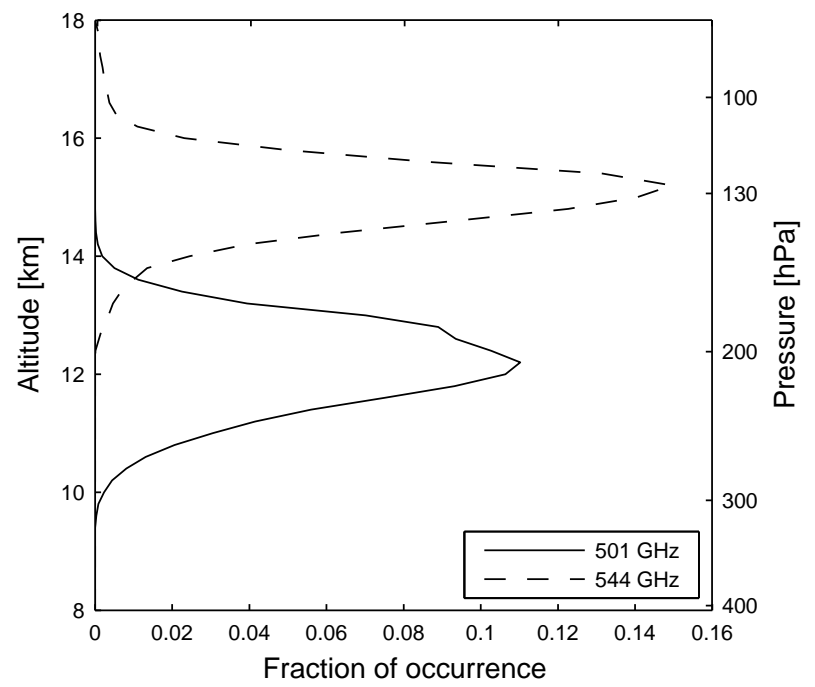

Fig. 1. The vertical distribution of Odin-SMR sounding levels. The altitude axis (on the left) is shown with a corresponding pressure axis (on the right) for a tropical model atmosphere.

\subsubsection{Cloud handling}

The methods for detection and correction of clouds are described in Ekström et al. (2007). In short, the observations are assigned a cloud influence based on the strength of a cloud signal, the spectral contrast between a strong emission line and continua channels. For thick clouds the inverted RHi is set to $100 \%$ whereas for clear-sky, i.e. no clouds, the RHi is unaltered. Between these two cases the cloud influence is assumed to vary linearly with the spectral contrast. The information extracted from the cloud correction method is also the basis for cloud ice mass retrievals (Eriksson et al., 2007).

\subsection{UARS-MLS}

The UARS-MLS observations cover the time period 19911997, with the major part of the measurements performed during the first three years. The instrument was originally not intended for measurements of UTH, but retrieval was possible using the $203 \mathrm{GHz}$ radiometer, targeting $\mathrm{ClO}$, as its field-of-view is scanned through the troposphere (Read et al., 1995, 2001). UARS-MLS has provided the longest series of microwave limb-sounding measurements of UTH that exist today and are considered to be of good quality. Up to now it has been the reference for global datasets and the results have been widely used for studies of the dynamics and climate effect of UTH and cirrus clouds.

\subsubsection{Data treatment}

UARS-MLS data are presently available in two versions, V4.90 and V5. For scientific investigations the V4.90 is rec-
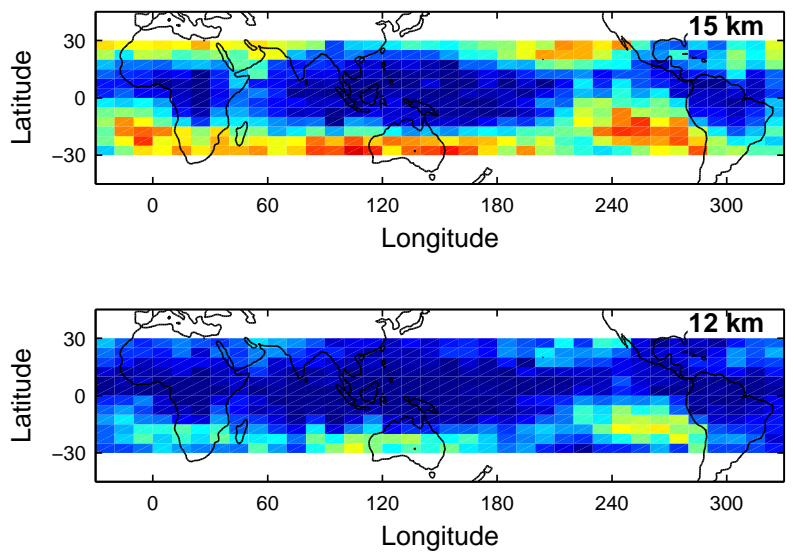

[\%]

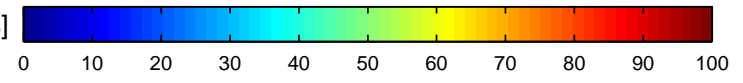

Fig. 2. Percentage of MIPAS retrievals without cloud influence at the sounding levels of Odin-SMR. The retrieved altitudes in the vertical profiles are filtered on visibility flag $(=1)$ and vertical resolution $(<7 \mathrm{~km})$. Only profiles in the tropical region have been considered.

ommended (Livesey et al., 2003). Data from the time period 1991-1997 have been used for UARS-MLS in this paper.

Humidity is retrieved on four pressure levels; 464, 316, 215 and $146 \mathrm{hPa}$, with estimated accuracies in the tropics of 58, 20, 20 and 34\% RHi, respectively. The vertical resolution of UARS-MLS UTH is around $3 \mathrm{~km}$ at 316 and $215 \mathrm{hPa}$ and somewhat coarser for the top and bottom layers. The general data usage recommendations in Read et al. (2001) have been considered, including truncation of high RHi (>120\%) to $100 \%$.

\subsubsection{Cloud handling}

The forward model used in the retrieval process does not include scattering. Detected scattering is instead handled by increasing the radiance uncertainty for the lower part of the scan, i.e. pressures larger than $300 \mathrm{hPa}$ (Read et al., 2001). Simulated clear-sky radiances are used to detect the scattering induced brightness temperature depression. Retrieval of cloud parameters from the UARS radiances has been performed for the first years of observations and a direct comparison of the UTH and cloud products revealed that UTH $>230 \%$ RHi are detected as cirrus. Supersaturated UTH from UARS MLS is also found to be correlated with indications of cirrus clouds from CLAES extinction measurements. This was interpreted as high humidities being an indication of cloud interference and the truncation of supersaturation above $120 \%$ was suggested. 


\subsection{Aura-MLS}

Following the successful UTH measurements of UARSMLS, RHi was included in the scientific objectives of AuraMLS (Waters et al., 2006). MLS has resumed the observations of upper tropospheric water vapour since the launch in July 2004. The retrieval process uses an iterative scheme (Livesey et al., 2006) where water vapour is retrieved from observations in the $190 \mathrm{GHz}$ band. The accuracies of the Aura MLS version 2.2 (v2.2) RHi at 215 and $121 \mathrm{hPa}$ are 35 and $25 \%$ of $\%$ RHi, respectively (Read et al., 2007). Their estimated precisions are 45 and $25 \%$, respectively.

\subsubsection{Data treatment}

The Aura MLS v2.2 data used here cover the time period September 2004 to June 2007. The official relative humidity product is derived from the $\mathrm{H}_{2} \mathrm{O}$ and temperature products using the Goff-Gratch formula (List, 1951). The vertical resolution of the v2.2 RHi is 5.5 and $5.0 \mathrm{~km}$ for 215 and $121 \mathrm{hPa}$, respectively (Read et al., 2007). In this study pressure levels ranging from 215 to $121 \mathrm{hPa}$ have been used and the recommendations for data usage of these pressure levels have been considered (Livesey et al., 2007).

Differences in the formulation of the saturation vapour pressure over ice between Goff-Gratch and Sonntag (1994), which is used for Odin-SMR inversions, are less than $0.2 \%$ in the temperature range $160-300 \mathrm{~K}$.

\subsubsection{Cloud handling}

Detection of clouds and initial retrieval of temperature and pressure are performed using clear-sky forward model calculations. Clouds are detected by comparing radiances from optically thin channels of the radiometers with simulations. The initial retrieval of temperature and pressure assumes $110 \%$ RHi in the forward model to get an upper limit on clear-sky radiances. Cloud influenced observations are either weighted less, as for the $190 \mathrm{GHz}$ band, or ignored. The threshold differences for cloud interference for each radiometer are empirically determined from simulations. After the final retrieval of $\mathrm{H}_{2} \mathrm{O}$ new radiances are calculated using the retrieved information to update the cloud flags of the observed radiances.

\subsection{MIPAS}

The MIPAS instrument is a Michelson Interferometer operated in the IR region. Measurements were performed from the launch of ENVISAT in March 2002 until September 2004. UTH has been retrieved both by ESA, using a near-realtime retrieval model (Ridolfi et al., 2000), and by the Institut für Meteorologie und Klimaforschung at Forschungszentrum Karlsruhe (IMK-FZK) in an offline retrieval dedicated to the UT/LS region (Milz et al., 2005).

\subsubsection{Data treatment}

The MIPAS UTH climatology considered here is based on water vapour and temperature products from IMK-FZK. The water vapour and temperature are converted to RHi using the same formula as for Odin-SMR (Sonntag, 1994). IMK-FZK uses a different retrieval approach than the operational nearrealtime ESA inversion, with more focus on the UT/LS region. The retrieval grid has $1 \mathrm{~km}$ spacing, which is narrower than the vertical resolution, $\sim 4 \mathrm{~km}$, and a smoothing constraint is applied to the profiles. The total uncertainty for the UT part of the profile is up to $30 \%$. A visibility flag is provided for each altitude in the retrieved profiles, so that cloud influenced retrieval altitudes can be screened. Only data without cloud influence have been accepted in the climatology.

The processing of MIPAS/IMK retrievals is presently ongoing and there are relatively few days of retrieved profiles available at the time of writing this paper. The filtered dataset is therefore sparse after cloud screening. The intercomparison with MIPAS data should therefore only be taken as an indication of MIPAS/IMK retrieval performance.

\subsubsection{Cloud handling}

UT observations in the infrared region suffer more from the impact of cloud ice interference than observations in the microwave region. The IMK-FZK retrieval has a rigorous cloud detection scheme and tangent altitudes with high cloud signatures are rejected. In the retrieved profiles the vertical resolution is drastically degraded, greater than $20 \mathrm{~km}$, in the presence of clouds. Evidence of the cloud influence can be seen in percentage of cloud free retrievals at the sounding altitudes of Odin-SMR (Fig. 2). Only in the driest regions, i.e. Pacific Ocean outside the coast of South America and sub-tropic latitudes, can MIPAS observe the upper troposphere humidity with high enough sampling rate.

\subsection{MOZAIC}

MOZAIC is a project for measurements of water vapour and ozone on board commercial aircrafts (Marenco et al., 1998). It is included here as it provides in-situ measurements with relatively high geographical coverage and can be used as reference for the satellite observations. The measurements are restricted to the flight corridors used by the commercial airlines. Luo et al. (2007, Fig. 1) show flight density over the tropical region, briefly the highest density in the tropics occurs over flight corridors going from Europe to Brazil, and Europe to South-East Asia. The Southern Hemisphere is sparsely covered with few airlines over continental Africa and along the Atlantic coast of South America. 


\subsubsection{Data treatment}

Measurements at cruise altitude, $>10 \mathrm{~km}$, in the tropical region during the period 2001-2004 are considered. Relative humidity is given with respect to water (RHw) and for the purpose of this paper it is converted to RHi using the same formula as for Odin-SMR inversions (Sonntag, 1994). The measurements of UTH have an accuracy of $5 \% \mathrm{RHw}$ and lower detection limit of 5\%RHw (Helten et al., 1998). At cruise altitudes the horizontal resolution is $15 \mathrm{~km}$.

\subsubsection{Cloud handling}

MOZAIC performs measurements both in clear and cloudy conditions and makes, in fact, no distinction between them. Spichtinger et al. (2004) used MOZAIC measurements to study the in-cloud humidity distribution, but the distinction between clear and cloud conditions was based on similar measurements during the INCA campaign (Ovarlez et al., 2002).

\section{Result and discussion}

The unit used in the comparison is RHi which, apart from MIPAS, is the retrieval unit of the included datasets. The vertical gradient of RHi in the troposphere is much weaker than the strong gradient in absolute amount of water vapour, making issues such as uncertainties in altitude and differences in vertical resolution less critical.

The datasets are compared in two ways, first as probability density functions (PDFs) of individual UTH measurements and then as seasonal geographical distributions. The PDFs will consequently be affected by both the accuracy and precision of the individual observations, whereas the comparison of seasonal geographic distributions is a test of the accuracy. Comparisons are performed for the $205 \mathrm{hPa}$ level, where there are data from UARS-MLS, Odin-SMR, AuraMLS and MOZAIC, and for the $127 \mathrm{hPa}$ level with data from Odin-SMR, MIPAS/IMK and Aura-MLS. The vertical profiles from UARS-MLS, Aura-MLS and MIPAS are interpolated in logarithmic pressure to the pressure levels of OdinSMR, with the exception of Aura-MLS in the upper layer where the retrieval level at $121 \mathrm{hPa}$ is used without interpolation.

\subsection{Considerations for creating climatologies}

The UTH products from the different instruments are used to produce climatologies. These climatologies then allow for an intercomparison of the UTH products on a systematic, longterm scale. The different datasets span different timeperiods, with a time gap of almost 10 years between UARS-MLS and the three later instruments, considering that the major part of UARS observations were made in the early 1990s. Based on HIRS observations of humidity in the altitude range 200 $500 \mathrm{hPa}$ during the timeperiod 1979-1998, Bates and Jackson (2001) found that the UTH trend in the tropical region is less than $3 \% /$ decade. The time gap of UARS-MLS to the other data sets is therefore considered to be of minor importance for the intercomparison.

On the other hand, even though the observations from Aura-MLS, Odin-SMR and MIPAS partly overlap the same timeperiod, they consistently observe the atmosphere at different solar times due to their different sun-synchronous orbits. The diurnal cycle in UTH is reported to have an amplitude of 2-6\% (Soden, 2000; Tian et al., 2004), with different peak-times for regions above ocean or land. However, as the amplitude of the diurnal cycle is relatively low compared to the accuracy of the individual measurements, this effect is also considered to be of minor importance here.

The climatologies are here limited to the tropical region, $30^{\circ} \mathrm{S}-30^{\circ} \mathrm{N}$, and are spatially averaged into gridboxes that span $5^{\circ}$ in latitude and $10^{\circ}$ in longitude. Soden and Bretherton (1996) have shown that there is an annual cycle in the UTH field, most pronounced over the monsoon regions with a half-year phase difference between the northern and southern side of the equator. To preserve these variations the climatologies are divided into four seasonal multi-year averages.

UARS-MLS and Aura-MLS have the most dense spatial coverage of the tropical upper troposphere. The coverage provided by Odin-SMR is controlled by the time-shared mission and further restricted by data screening, resulting in sparser spatial and temporal coverage than the MLS instruments. MIPAS observations are restricted by cloud occurrences and MOZAIC measurements are only performed along the flight corridors of commercial airlines.

In the comparisons the datasets are resampled to give similar geographical coverage, thereby taking into account the zonal and meridional structures of the humidity fields. This is done by calculating the fraction of measurements within the $5^{\circ} \times 10^{\circ}$ gridboxes for the sparser dataset and then randomly resampling the denser datasets to get the same relative distribution among the gridboxes. Where this has been applied is indicated in the description of each individual comparison case.

As MIPAS is sensitive to thinner clouds than the microwave instruments can detect, the comparison with MIPAS only considers cloud free observations. Averaged over the tropical region roughly $15 \%$ of the MIPAS data reach down to $12 \mathrm{~km}(205 \mathrm{hPa})$, and $33 \%$ down to $15 \mathrm{~km}(127 \mathrm{hPa})$. To put this in context, it can be noted that $70 \%$ of Odin-SMR observations do not have any cloud signature and only $8 \%$ are considered thick clouds. In the comparison of MIPAS with Odin-SMR and Aura-MLS only the upper layer is considered in order to get robust statistics. 


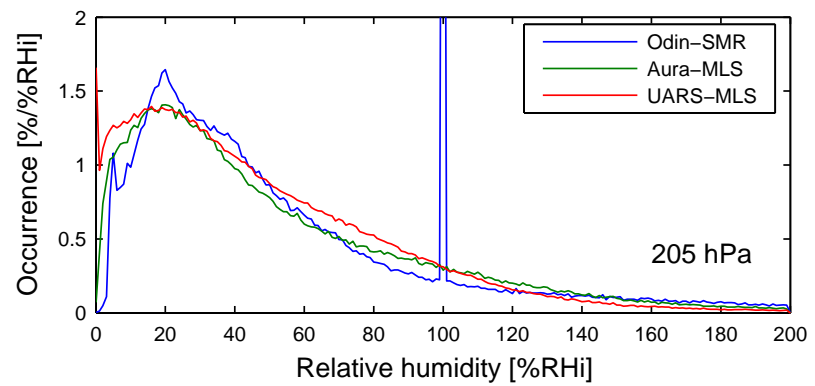

Fig. 3. Global PDF of UTH at $205 \mathrm{hPa}$ from Odin-SMR, UARSMLS, Aura-MLS measurements.

\subsection{Humidity probability distribution functions}

The PDF of measured UTH is studied for each dataset, without truncation of supersaturation. This approach makes it possible to evaluate the consistency between datasets without the need of co-location in space and time, and has been used in similar studies of other trace-gas retrievals (Lary and Lait, 2006). The difference in horizontal resolution between MOZAIC and satellite limb-sounding is significant. However, by averaging the MOZAIC timeseries over length scales comparable to the typical foot-print size of satellite limb-sounding observations $(\sim 100-200 \mathrm{~km})$, it was found that this difference has low importance for the resulting PDF. This behaviour can be explained by the long correlation length found in MOZAIC data. Observations of icesupersaturated regions have for example been found to have a mean path-length of $150 \mathrm{~km}$ (Gierens and Spichtinger, 2000). No additional averaging has been applied to the MOZAIC observations.

The PDFs of UTH are presented in four groups; first the $205 \mathrm{hPa}$ PDFs are shown, one with global coverage and one along the flight routes of MOZAIC, then the $127 \mathrm{hPa}$ PDFs are presented for measurements with all-weather conditions and one case with only clear-sky observations. All PDFs have been normalised over their whole range of UTH measurements, however for clarity the figures only cover the range 0-200\% RHi.

Figure 3 shows the global humidity PDFs at $205 \mathrm{hPa}$ for Odin-SMR, Aura-MLS and UARS-MLS. The PDFs of the three datasets show similar shapes. The structures in OdinSMR PDF at 5, 20 and $40 \%$ RHi are due to the non-linear behaviour of the transfer function at dry conditions. Due to the longer wavelengths, the MLS observations are even less sensitive to clouds than Odin-SMR. The spike at $100 \%$ RHi in Odin-SMR data is due to the cloud correction method (Sect. 2.1.2) and the differences around 100\%RHi can be seen as a measure on the instruments relative sensitivity to cloud influence.

In Fig. 4 the satellite observations have been resampled

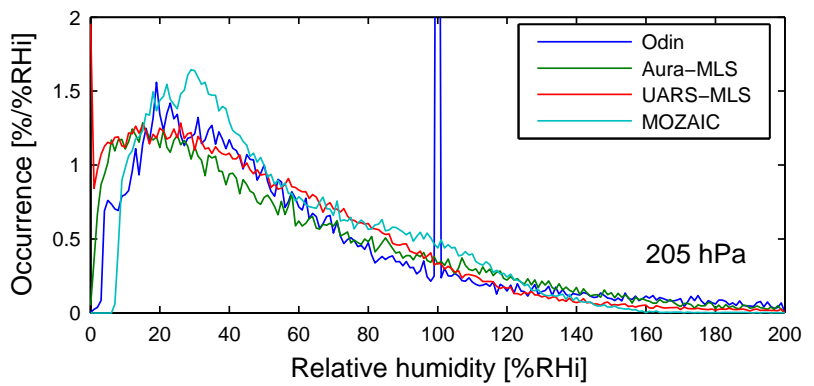

Fig. 4. PDF of Odin-SMR, UARS-MLS, Aura-MLS and MOZAIC measurements of UTH at $205 \mathrm{hPa}$. Only the regions around the flight corridors of MOZAIC are considered.

to give similar geographic coverage as MOZAIC, i.e. most measurements along flight routes from Europe to South East Asia and South America. For these conditions, the microwave limb-sounding PDFs agree well with that of the insitu measurements. MOZAIC has relatively higher occurrences around 100\%RHi than any of the satellite datasets, giving it a bimodal distribution with a lower mode around $30 \%$ RHi and an upper mode around $100 \%$ RHi. Luo et al. (2007) have also shown bimodality present in MOZAIC data with the relative strength of the two modes varying with season and region. This bimodality is a signature of mixing of different airmasses (Zhang et al., 2003), one mode associated with moistening (convection) and the other with drying (subsidence). Spichtinger et al. (2004) associated the second, upper, mode in MOZAIC data more specifically with cloud occurrence and used it to infer in-cloud RHi distributions.

There are several reasons why the satellite observations do not have bimodal PDFs. First, the random retrieval errors act to smear out the bimodality. The estimated precisions of the individual observations of the microwave limb-sounders at $205 \mathrm{hPa}$ are $15-45 \%$. This is probably the strongest reason. Secondly, microwave measurements also have a small bias towards clear-sky observations. Strong cloud influence tends to obscure the humidity information, and such observations are more likely to be discarded as erroneous. For example, $8 \%$ of the Odin-SMR observations at $501 \mathrm{GHz}$ observations have strong cloud influence. In these cases the Odin-SMR retrieval sets the UTH to $100 \% \mathrm{RHi}$, as this is our best estimate of the in-cloud humidity. Thus measurements with strong cloud signature are still considered, giving a crude bimodal distribution.

With higher altitude in the troposphere, the saturation pressure decreases and zonal mixing becomes more important. As a consequence the humidity field at $127 \mathrm{hPa}$ has less structure and is generally higher than at $205 \mathrm{hPa}$. This can be seen in the PDFs of Odin-SMR and Aura-MLS at $127 \mathrm{hPa}$, compared in Fig. 5. The spatial density of the Odin-SMR $127 \mathrm{hPa}$ data are strongly affected by the data screening for 
the $544 \mathrm{GHz}$ frequency band. Aura-MLS has therefore been resampled to only compare observations with the same geographic coverage. The two satellite datasets have unimodal PDFs with the maximum frequency shifted toward higher humidities. The spike in Odin-SMR at $100 \%$ RHi represents thick clouds.

Most MIPAS/IMK cloud free observations are located to regions with dry average conditions, e.g. southern Pacific Ocean (Fig. 2). To decrease the influence of clouds, OdinSMR data are filtered on cloud influence and then resampled to give the same geographical coverage as MIPAS. AuraMLS data from the same regions are also shown in the figure, but without cloud filtering. The cloud influence on AuraMLS should in these regions be very small. The resulting MIPAS dataset is sparse and only PDFs for the upper level are shown, averaged over 5\% RHi in Fig. 6. It should be noted that these represent the humidity in dry regions, in comparison with the all-weather PDFs (Fig. 5) that have global coverage. The high frequency of dry conditions and low frequency of supersaturation is therefore partly attributed to the regional conditions.

The UTH PDFs of the different instruments agree very well with each other within the four cases. At $205 \mathrm{hPa}$ both on the global scale and in the comparison with in-situ measurements, the satellite PDFs give a common view on the humidity. For the $127 \mathrm{hPa}$ level the Odin-SMR vs. Aura-MLS comparison and the cloud free comparison of Odin-SMR, MIPAS/IMK and Aura-MLS have similarly high agreement. The MIPAS dataset is however relatively sparse and the result should be taken as indicative.

All datasets have exponential type PDFs, at $205 \mathrm{hPa}$ for humidities $>20 \% \mathrm{RHi}$ and at $127 \mathrm{hPa}>50 \% \mathrm{RHi}$, this behaviour has been investigated by Gierens et al. (1999) who also provides an explanation of the processes leading to it. Spichtinger et al. (2003) used the exponential PDF of RHi found in UARS-MLS data to study ice supersaturated regions, they report average frequencies of occurrence for ice supersaturation in cloud-cleared measurements from the tropical region to be $6 \%$ for $215 \mathrm{hPa}$ and $19 \%$ at $146 \mathrm{hPa}$. Similar frequencies are found for Odin-SMR clear-sky observations, with $5 \%$ at $205 \mathrm{hPa}$ and $12 \%$ at $127 \mathrm{hPa}$. The occurrence of high ice supersaturation has been observed by other measurements as well (Jensen et al., 2005) and different hypotheses for persistant supersaturation have been suggested (Peter et al., 2006). Even though high supersaturation has been observed in cloud free regions, not all of them are real cases of supersaturation. High humidity and thin cirrus clouds are difficult to distinguish in remote sensing and a portion of the high supersaturated observations seen in Figs. 3 and 5 are potentially cloud effects. Notably, in the clearsky PDFs the fraction of occurrence drops close to zero at $\sim 130 \%$ RHi (Fig. 6).

The relatively high occurrence of supersaturation in OdinSMR should not be completely assigned to the atmospheric state. Instead it is an indication of the large random uncer-

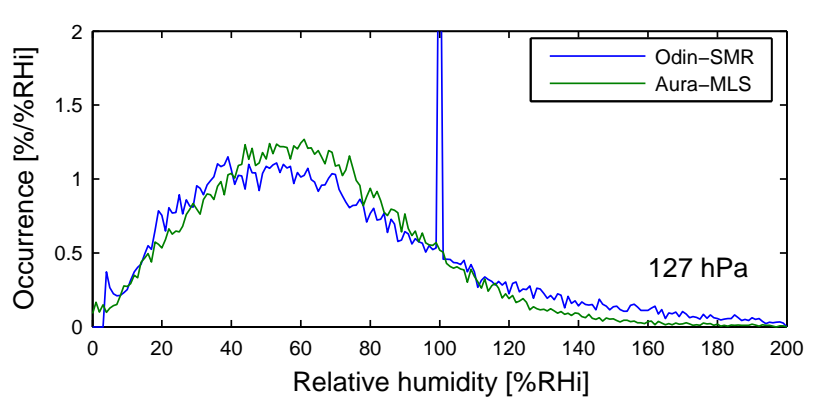

Fig. 5. Global PDF of UTH at $127 \mathrm{hPa}$ from Odin-SMR and AuraMLS.

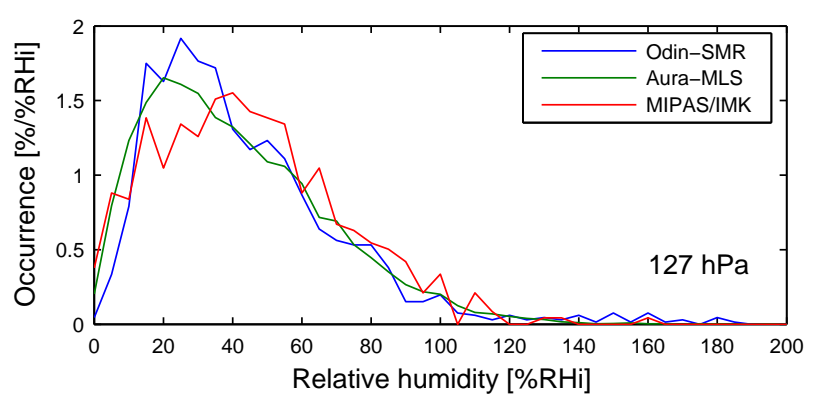

Fig. 6. PDF of cloud free Odin-SMR observations, MIPAS/IMK and all-weather Aura-MLS at $127 \mathrm{hPa}$. Only regions where there remain sufficient number of measurements from both MIPAS/IMK after cloud filtering, and Odin-SMR after the data screening of the $544 \mathrm{GHz}$ band, are considered. The major part of the measurements are from the dry region over the South Pacific.

tainty in the measurements. As pointed out by Buehler and Courcoux (2003) the exponential PDF of remotely measured RHi can partly be explained by temperature uncertainties. In the case of Odin-SMR, this is also true for calibration uncertainties (Ekström et al., 2007). Observations of high supersaturation should not be discarded as erroneous. However, for Odin-SMR such values should be treated with caution.

\subsection{Geographical distributions}

Seasonal climatologies of UTH have already been presented elsewhere for UARS-MLS (Read et al., 2001) and OdinSMR (Ekström et al., 2007). Here, the average geographical distribution of UTH over each instrument's mission timeperiod are shown to give a feeling of the average humidity fields. The two horizontal layers are presented in Figs. 7 and 8, respectively. The data have been averaged into $5^{\circ} \times 10^{\circ}$ gridboxes and supersaturation above $140 \% \mathrm{RHi}$ has been set to $100 \% \mathrm{RHi}$. The general agreement of the different datasets is clearly seen, where the smoothness of the two MLS datasets indicates the larger amount of observations available. 

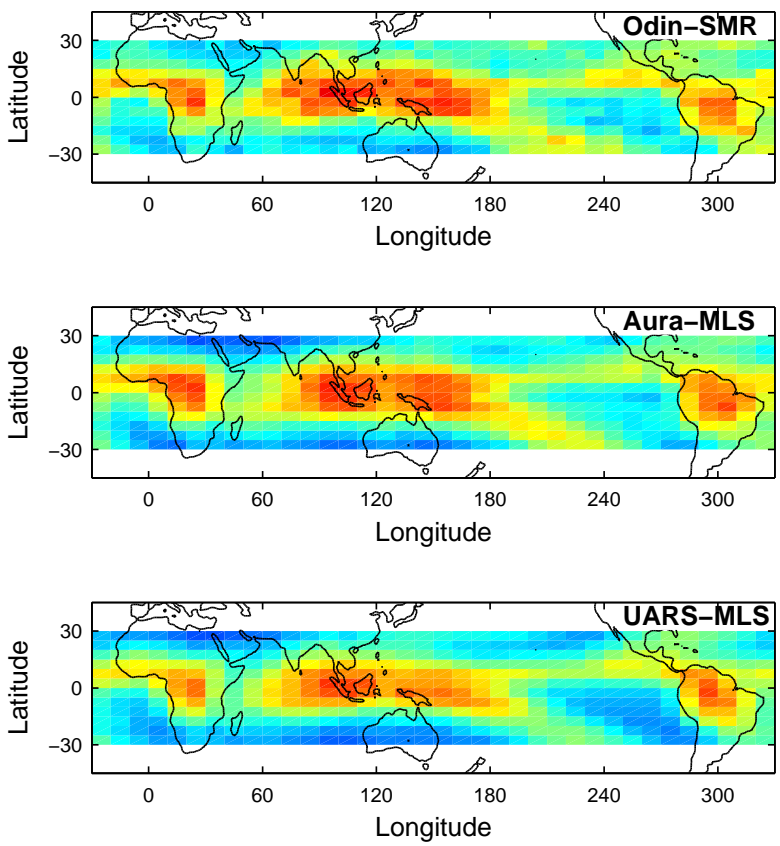

[\% $\mathrm{RHi}]$

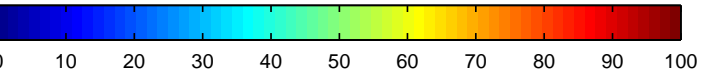

Fig. 7. Multiyear average UTH at $205 \mathrm{hPa}$. Odin-SMR covers 2001-2007, Aura-MLS 2004-2007 and UARS-MLS 1991-1997.

At $205 \mathrm{hPa}$ high humidity is found over regions of strong convection, the maritime continent, South America, central Africa and along the Inter-Tropical Convergence Zone (ITCZ). The seasonal variations give the annual averages a meridional smearing and the ITCZ displayed as two distinct lines across the Pacific Ocean. The three instruments have good morphological and quantitative agreement.

The geographical distribution of UTH at $127 \mathrm{hPa}$ (Fig. 8) shows that the humidity field is more controlled by zonal mixing than local convection (Sassi et al., 2001), and that the average humidity is closer to saturation. Aura-MLS has much drier averages in the sub-tropical regions, i.e. latitudes higher than $20^{\circ} \mathrm{N}$ and $20^{\circ} \mathrm{S}$. At these latitudes the stratosphere frequently descend down to $121 \mathrm{hPa}$. While MLS has the capability to measure during these events, the current Odin-SMR retrieval requires a temperature lapse rate associated with tropospheric air. The Odin-SMR averages shown in the figure are therefore only representative for UT humidities, whereas MLS also includes LS humidities.

\subsection{Mean value comparison}

To compare the geographical distributions in more detail the data are grouped in four seasons and latitude-longitude gridboxes of $5^{\circ} \times 10^{\circ}$. The gridbox averages from the microwave limb-sounders are plotted against each other (Figs. 9-12).
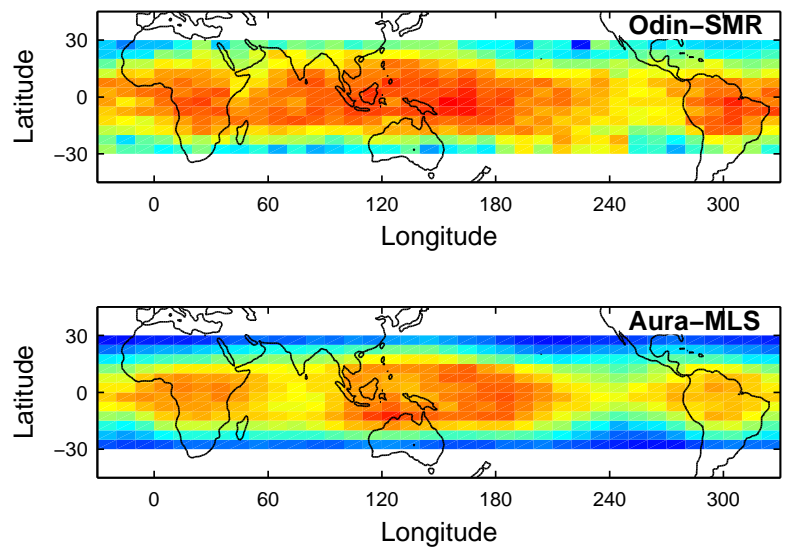

[\% $\mathrm{RHi}]$

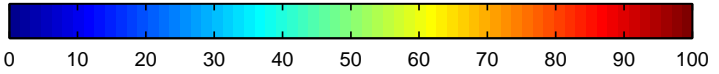

Fig. 8. Multiyear average UTH at $127 \mathrm{hPa}$. Odin-SMR covers 2001-2007 and Aura-MLS 2004-2007.

The estimated global average accuracy for Odin-SMR is $\sim 13 \% \mathrm{RHi}$, for UARS-MLS 20-30\%RHi, and for Aura-MLS $\sim 15 \%$ RHi. The random uncertainties of the averaged UTH from all three datasets are very small, $\sim 1 \%$ RHi. Principal component analysis has been used to perform orthogonal regressions on the scattered gridbox averages. The linear equations of the regressions are printed together with the rootmean-square (RMS) of the residuals in each corresponding figure. The scatter plots show overall very good agreement.

Scatter plots of Odin-SMR and Aura-MLS are shown in Figs. 9 and 10. In both cases the scatter plots show overall good agreement for the gridbox averages. The regression lines have slopes close to one and only small negative intercepts ( $\sim 5 \% \mathrm{RHi})$. At $205 \mathrm{hPa}$ the slope of the regression line is slightly larger, suggesting a $10 \%$ deviation from the oneto-one relationship. Taking into account the negative intercept, the average differences are still below 10\% RHi. In the upper layer, at $127 \mathrm{hPa}$, there are fewer datapoints available for Odin-SMR, which is reflected by the relatively higher spread of the averaged values. The RMS of the residuals are 6.3 and $9 \%$ RHi at the upper and lower levels, respectively.

Figure 11 shows the scatter plot of Odin-SMR against UARS-MLS averages at $205 \mathrm{hPa}$. These two datasets also show a very good agreement, with the slope of the fitted line close to one. Similar to the Aura-MLS comparison the regression indicates a positive bias in Odin-SMR compared to UARS-MLS of 5\%RHi and also a similar spread of the residuals.

Gridbox averages from the two MLS instruments are scatter plotted against each other in Fig. 12. Comparisons of these two datasets are included here only in the context of the comparison with Odin-SMR. The two MLS datasets are more dense than Odin-SMR and allow for a more detailed 


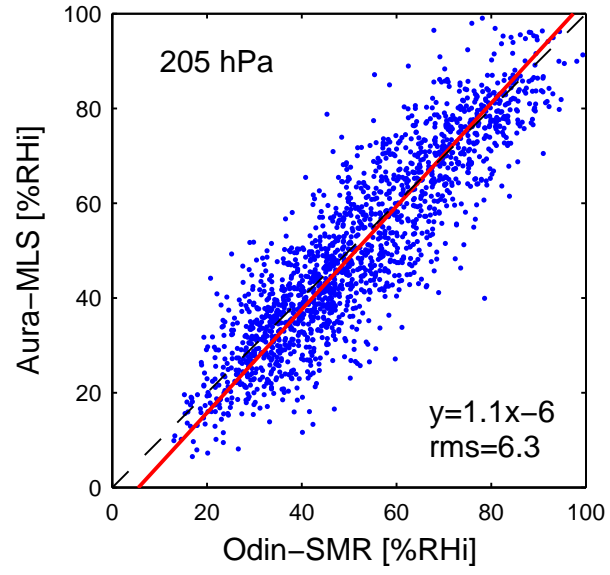

Fig. 9. Scatter plot of gridbox averages of Odin-SMR and AuraMLS UTH at $205 \mathrm{hPa}$. The plot also show the regression (red line) with the equation and RMS residual in the lower right corner, and a one-to-one reference line (dashed).

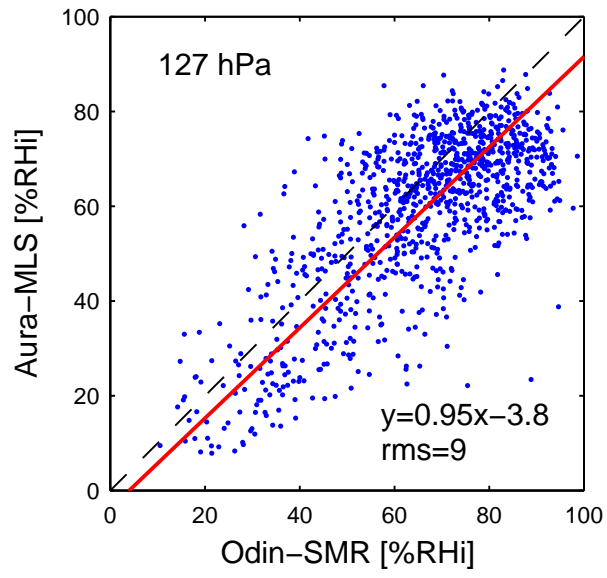

Fig. 10. Scatter plot of gridbox averages of Odin-SMR and AuraMLS UTH at $127 \mathrm{hPa}$. The plot also show the regression (red line) with the equation and RMS residual in the lower right corner, and a one-to-one reference line (dashed).

comparison. However, here the datasets are presented in form of gridbox averages to be in line with their individual comparisons to Odin-SMR (Figs. 9 and 11). The slope of the regression line is similar to that found between Odin-SMR and AURA-MLS, which is expected since the fitted line in Fig. 11 is close to one. But in contrast to that comparison, there seems to be no systematic offset, instead the intercept is close to zero. Compared to Aura-MLS, the gridbox averages of UARS-MLS are drier with $10 \%$ relative difference.

The spread of the UTH averages is relatively similar in all three comparisons of $205 \mathrm{hPa}$ data. Since the random uncertainties of the datasets have been practically averaged out, the spread reflects the natural variations within the years and seasons considered.

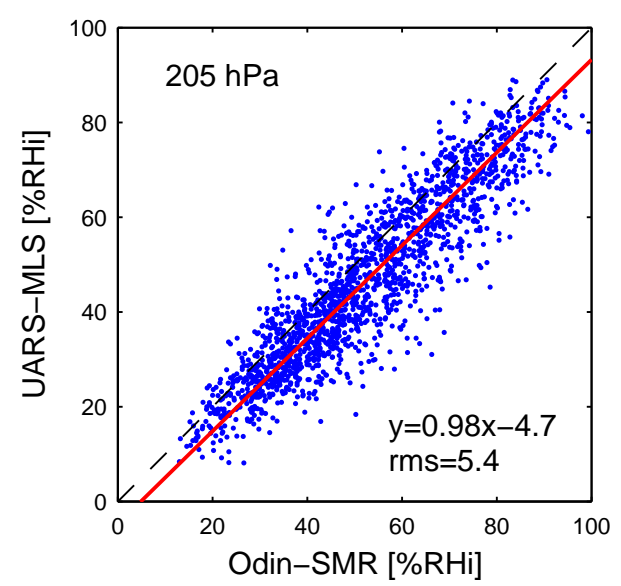

Fig. 11. Scatter plot of gridbox averages of Odin-SMR and UARSMLS UTH at $205 \mathrm{hPa}$. The plot also show the regression (red line) with the equation and RMS residual in the lower right corner, and a one-to-one reference line (dashed).

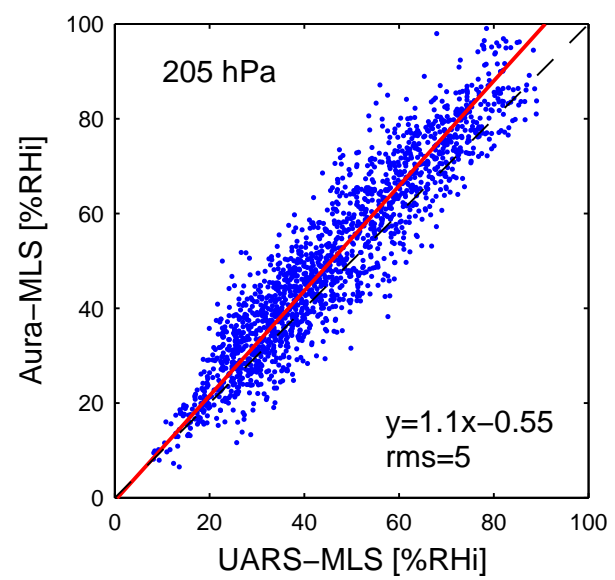

Fig. 12. Scatter plot of gridbox averages of Aura-MLS and UARSMLS UTH at $205 \mathrm{hPa}$. The plot also show the regression (red line) with the equation and RMS residual in the lower right corner, and a one-to-one reference line (dashed).

\subsection{Cloud sensitivity}

Odin-SMR UTH observations with strong cloud influence are not discarded in the retrieval, but assigned a priori value for the in-cloud humidity. For moderate cloud signature a linear transition between clear-sky and saturated cloud is applied. The observations with strong cloud influence are seen as the high values at $100 \%$ RHi in the PDFs (Figs. 3 and 5). For these cases the uncertainty is equal to the a priori uncertainty, $\sim 20 \%$ RHi, but for moderate cases the uncertainty also depends on the cloud classification criteria. To investigate the sensitivity of Odin-SMR UTH to cloud influence the current cloud correction scheme is compared to three alternative 

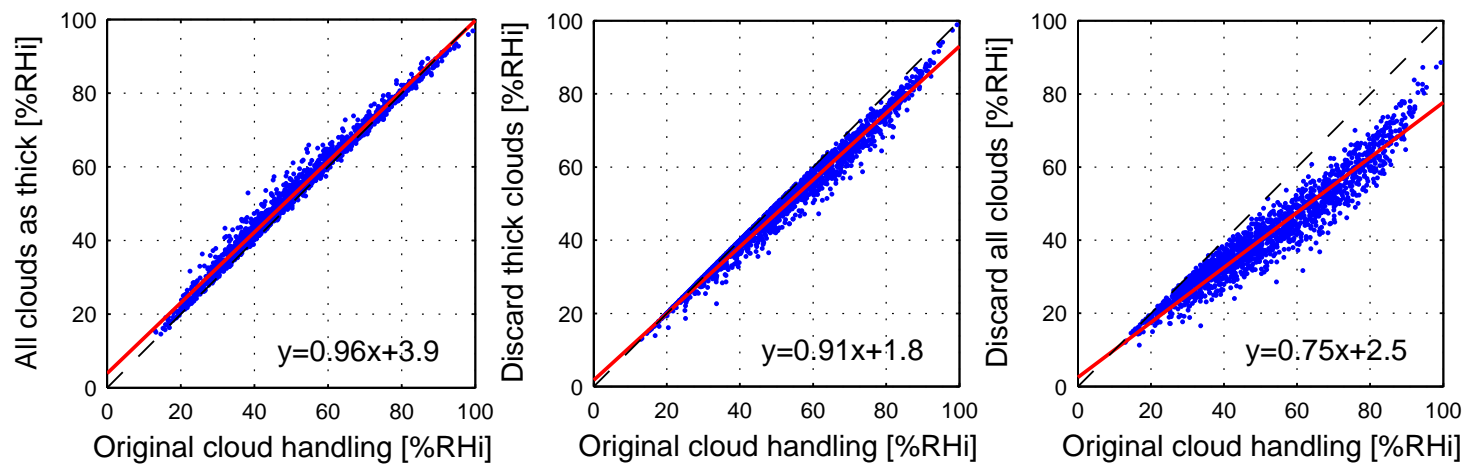

Fig. 13. Scatter plot of seasonal average UTH for alternative constraints on cloud handling compare to the original cloud handling.

methods. These methods are; treating all observations with any cloud signature as strong (i.e. set to $100 \%$ RHi), discarding observations with strong cloud signature and the more strict method of discarding all observations with any cloud signature. The effect of these three alternative methods on the gridbox averages are shown in Fig. 13.

The first two methods, representing realistic changes to the cloud correction, only introduce differences less than $10 \%$ RHi on the gridbox averages. This value can be taken as an estimate of the systematic uncertainty introduced by the current cloud correction scheme. The more extreme method of discarding all observations with any cloud influence differs by up to $20 \%$ RHi for mid-high humidities (60$80 \% \mathrm{RHi}$ ). This, on the other hand, stresses the point that measurements with cloud influence, even at $500 \mathrm{GHz}$, have to be included in order to provide a correct estimate of the overall average humidity.

\section{Conclusions}

The comparisons of UTH PDF and the seasonal geographic averages show that the observations of Odin-SMR, UARSMLS and Aura-MLS agree well. The comparison of the seasonal geographic averages show that the average systematic difference is less than $10 \%$ RHi for all considered instruments and pressure levels. For low humidities the MLS instruments have similar values, whereas for higher humidities it is OdinSMR and Aura-MLS that are similar. The intercepts of the orthogonal regressions suggest a potential small positive bias in Odin-SMR, 5\% RHi, compared to the MLS instruments.

All three instruments have long tails of supersaturation in their PDFs, which can partly be attributed to retrieval uncertainties such as observation noise and cloud contamination. These high values should be handled with caution when constructing climatologies. Taking into account the quality and amount of the data, the $205 \mathrm{hPa}$ data have the best conditions for the comparison and also show the best agreement between the datasets.
The systematic uncertainty introduced by the cloud correction on Odin-SMR humidities was found to be on the order of $10 \%$ RHi. The cloud correction and the calibration uncertainty are potential sources to the positive bias found between Odin-SMR and the MLS datasets.

The comparison between MIPAS, Odin clear-sky observations and Aura-MLS, should be considered as preliminary as the first two datasets are sparse. The results indicate that there is a good agreement for relatively cloud free regions. However, as large parts of the tropical region are associated with frequent cloud cover, the MIPAS measurements can not give a global picture of the tropics. In particular, only $33 \%$ of the retrieved profiles were found to reach down to $127 \mathrm{hPa}$. This stresses the importance of using microwave sounding for the upper troposphere, as there is frequent cloud occurrence in this region.

Even though the microwave limb-sounders give similar views of the UTH, it is still important to compare that methodology with other measurement geometries and techniques. The agreement with MOZAIC is important, in the sense that it verifies that the "microwave limb-sounding view" is similar to what in-situ instruments see in the UT.

The high agreement found between the three microwave limb-sounding measurements is encouraging. The three microwave limb-sounders are similar in viewing geometry and vertical resolution, but as they use different instrumental solutions and spectroscopic parameters they can be treated as independent measurements. This study does not only give more confidence in the newer datasets, Odin-SMR and AuraMLS, but also in the UARS-MLS measurements and the studies based on those data (e.g. Minschwaner and Dessler, 2004; Jiang et al., 2004). Considering the temporal coverage and the high sampling rate, the dense dataset of Aura-MLS could conclusively be regarded as the most complete view on the UTH available today. It should however be remarked that whenever possible, relative humidity should be accompanied with information or at least indication of clouds. Otherwise important information on the radiative and dynamic state of the atmosphere is lost. 
Acknowledgements. The MOZAIC programme and the involved airlines (Lufthansa, AirFrance, Austrian and former Sabena) are acknowledged for making the MOZAIC measurements possible. The MOZAIC data were provided from the MOZAIC Data Base. This work has been funded by the Swedish National Graduate School in Space Technology and the Swedish Space Board. The Odin-SMR UTH dataset is based on essential contributions from the Odin-SMR retrieval group and the ARTS community.

Edited by: G. Vaughan

\section{References}

Barath, F. T., Chavez, M. C., Cofield, R. E., Flower, D. A., Frerking, M. A., Gram, M. B., Harris, W. M., Holden, J. R., Jarnot, R. F., Kloezeman, W. G., Klose, G. J., Lau, G. K., Loo, M. S., Maddison, B. J., Mattauch, R. J., McKinney, R. P., Peckham, G. E., Pickett, H. M., Siebes, G., Soltis, F. S., Suttie, R. A., Tarsala, J. A., Waters, J. W., and Wilson, W. J.: The Upper Atmosphere Research Satellite microwave limb sounder instrument, J. Geophys. Res., 98, 10751-10 762, 1993.

Bates, J. J. and Jackson, D. L.: Trends in upper-tropospheric humidity, Geophys. Res. Lett., 28, 1695-1698, 2001.

Buehler, S. A. and Courcoux, N.: The impact of temperature errors on perceived humidity supersaturation, Geophys. Res. Lett., 30, 1759, doi:10.1029/2003GL017691, 2003.

Croskey, C. L., Kämpfer, N., Belivacqua, R. M., Hartmann, G. K., Kunzi, K. F., Schwartz, P. R., Olivero, J. J., Puliafito, S. E., Aellig, C., Umlauft, G., Waltman, W. B., and Degenhardt, W.: The Millimeter Wave Atmospheric Sounder (MAS): A Shuttle-Based Remote Sensing Experiment, IEEE Trans. Microwave Theory Techn., 40, 1090-1100, 1992.

Ekström, M., Eriksson, P., Rydberg, B., and Murtagh, D. P.: First Odin sub-mm retrievals in the tropical upper troposphere: humidity and cloud ice signals, Atmos. Chem. Phys., 7, 459-469, 2007 , http://www.atmos-chem-phys.net/7/459/2007/.

Eriksson, P., Ekström, M., Rydberg, B., and Murtagh, D. P.: First Odin sub-mm retrievals in the tropical upper troposphere: ice cloud properties, Atmos. Chem. Phys., 7, 471-483, 2007, http://www.atmos-chem-phys.net/7/471/2007/.

Fischer, H. and Oelhaf, H.: Remote Sensing of vertical profiles of atmospheric trace constituents with MIPAS limb emission spectrometers, Appl. Optics, 35, 2787-2796, 1996.

Frisk, U., Hagström, M., Ala-Laurinaho, J., Andersson, S., Berges, J. C., Chabaud, J. P., Dahlgren, M., Emrich, A., Florén, H. G., Fredrixon, M., Gaier, T., Haas, R., Hirvonen, T., Hjalmarsson, A., Jakobsson, B., Jukkala, P., Kildal, P. S., Kollberg, E., Lassing, J., Lecacheux, A., Lehikoinen, P., Lehto, A., Mallat, J., Marty, C., Michet, D., Narbonne, J., Nexon, M., Olberg, M., Olofsson, A. O. H., Olofsson, G., Origné, A., Petersson, M., Piironen, P., Pons, R., Pouliquen, D., Ristorcelli, I., Rosolen, C., Rouaix, G., Räisänen, A. V., Serra, G., Sjöberg, F., Stenmark, L., Torchinsky, S., Tuovinen, J., Ullberg, C., Vinterhav, E., Wadefalk, N., Zirath, H., Zimmermann, P., and Zimmermann, R.: The Odin satellite I. Radiometer design and test, Astron. Astrophys., 402, L27-L34, doi:10.1051/0004-6361:20030335, 2003.

Gierens, K. and Spichtinger, P.: On the distribution of icesupersaturated regions in the upper troposphere and lowermost stratosphere, Ann. Geophys., 18, 499-504, 2000, http://www.ann-geophys.net/18/499/2000/.

Gierens, K., Schumann, U., Helten, M., Smit, H., and Marenco, A.: A distribution law for relative humidity in the upper troposphere and lower stratosphere derived from three years of MOZAIC measurements, Ann. Geophys., 17, 1218-1226, 1999, http://www.ann-geophys.net/17/1218/1999/.

Gille, J. C., Bailey, P. L., and Russell, J. M.: Temperature and Composition Measurements from the 1.r.i.r. and l.i.m.s. Experiments on Nimbus 6 and 7, Phil. Trans. R. Soc. A, 296, 205-218, 1980.

Harries, J. E.: Atmospheric radiation and atmospheric humidity, Q. J. Roy. Meteor. Soc., 123, 2173-2186, 1997.

Helten, M., Smit, H. G. J., Sträter, W., Kley, D., Nedelec, P., Zöger, M., and Busen, R.: Calibration and preformance of automatic compact instrumentation for the measurement of relative humidity from passenger aircraft, J. Geophys. Res., 103, 25643 $25652,1998$.

Jensen, E. J., Smith, J. B., Pfister, L., Pittman, J. V., Weinstock, E. M., Sayres, D. S., Herman, R. L., Troy, R. F., Rosenlof, K., Thompson, T. L., Fridlind, A. M., Hudson, P. K., Cziczo, D. J., Heymsfield, A. J., Schmitt, C., and Wilson, J. C.: Ice supersaturations exceeding $100 \%$ at the cold tropical tropopause: implications for cirrus formation and dehydration, Atmos. Chem. Phys., 5, 851-862, 2005, http://www.atmos-chem-phys.net/5/851/2005/.

Jiang, J. H., Wang, B., Goya, K., Hocke, K., Eckermann, S. D., Ma, J., Wu, D. L., and Read, W. G.: Geographical distribution and interseasonal variability of tropical deep convection: UARS MLS observations and analyses, J. Geophys. Res., 109, D03111, 1-19, 2004.

Kley, D., Russell III, J. M., and Phillips, C. (Eds.): SPARC Assessment of Upper Tropospheric and Stratospheric Water Vapour, WCRP - No. 113, WMO/TD - No. 1043, SPARC Report No. 2, Paris, 2000.

Lary, D. J. and Lait, L.: Using Probability Distribution Functions for Satellite Validation, IEEE Trans. Geosci. Rem. Sens., 44, 1359-1366, 2006.

List, R. J.: Smithsonian Meteorological Tables, Smithson. Misc. Collect. 114, Smithson. Inst., Washington, D.C., 1951.

Livesey, N. J., Read, W. G., Froidevaux, L., Waters, J. W., Santee, M. L., Pumphrey, H. C., Wu, D. L., Shippony, Z., and Jarnot, R. F.: The UARS Microwave Limb Sounder version 5 data set: Theory, characterization, and validation, J. Geophys. Res., 108, 4378, doi:10.1029/2002JD002273, 2003.

Livesey, N. J., Snyder, W. V., Read, W. G., and Wagner, P. A.: Retrieval algorithms for the EOS Microwave Limb Sounder (MLS), IEEE Trans. Geosci. Rem. Sens., 44, 1144-1155, doi: 10.1109/TGRS.2006.872327, 2006.

Livesey, N. J., Read, W. G., Lambert, A., Cofield, R. E., Cuddy, D. T., Froidevaux, L., Fuller, R. A., Jarnot, R. F., Jiang, J. H., Jiang, Y. B., Knosp, B. W., Kovalenko, L. J., Pickett, H. M., Pumphrey, H. C., Santee, M. L., Schwartz, M. J., Stek, P. C., Wagner, P. A., Waters, J. W., and Wu, D. L.: Earth Observing System (EOS) Microwave Limb Sounder (MLS) Version 2.2 Level 2 data quality and description document, JPL Tech. Doc. D-33509, Jet Propulsion Lab., Pasadena, CA, 2007.

Luo, Z., Kley, D., Johnson, R. H., and Smit, H.: Ten Years of Measurements of Tropical Upper-Tropospheric Water Vapor by MOZAIC. Part I: Climatology, Variability, Transport, and Rela- 
tion to Deep Convection, J. Climate, 20, 418-435, 2007.

Marenco, A., Thouret, V., Nédélec, P., Smit, H., Helten, M., Kley, D., Karcher, F., Simon, P., Law, K., Pyle, J., Poschmann, G., von Wrede, R., Hume, C., and Cook, T.: Measurement of ozone and water vapor by Airbus in-service aircraft: The MOZAIC airborne program, an overwiew, J. Geophys. Res., 103, 25 631-25 642, 1998.

Milz, M., von Clarmann, T., Fischer, H., Glatthor, N., Grabowski, U., Höpfner, M., Kellman, S., Kiefer, M., Linden, A., Tsidu, G. M., and Stiller, G. P.: Water vapor distributions measured with the Michelson Interferometer for Passive Atmospheric Sounding on board Envisat (MIPAS/Envisat), J. Geophys. Res., 110, D24307, doi:10.1029/2005JD005973, 2005.

Minschwaner, K. and Dessler, A. E.: Water vapor feedback in the tropical upper troposphere: Model results and observations, J. Climate, 17, 1272-1282, 2004.

Murtagh, D., Frisk, U., Merino, F., Ridal, M., Jonsson, A., Stegman, J., Witt, G., Eriksson, P., Jiménez, C., Megie, G., de La Noë, J., Ricaud, P., Baron, P., Pardo, J. R., Hauchcorne, A., Llewellyn, E. J., Degenstein, D. A., Gattinger, R. L., Lloyd, N. D., Evans, W. F. J., McDade, I. C., Haley, C., Sioris, C., von Savigny, C., Solheim, B. H., McConnell, J. C., Strong, K., Richardson, E. H., Leppelmeier, G. W., Kyrölä, E., Auvinen, H., and Oikarinen, L.: An overview of the Odin atmospheric mission, Can. J. Phys., 80, 309-319, 2002.

Nordh, H. L., von Schéele, F., Frisk, U., Ahola, K., Booth, R. S., Encrenaz, P. J., Hjalmarson, A., Kendall, D., Kyrölä, E., Kwok, S., Lecacheux, A., Leppelmeier, G., Llewellyn, E. J., Mattila, K., Mégie, G., Murtagh, D., Rougeron, M., and Witt, G.: The Odin orbital observatory, Astron. Astrophys., 402, L21-L25, doi: 10.1051/0004-6361:20030334, 2003.

Ovarlez, J., Gayet, J.-F., Gierens, K., Ström, J., Ovarlez, H., Auriol, F., Busen, R., and Schumann, U.: Water vapour measurements inside cirrus clouds in Northern and Southern hemispheres during INCA, Geophys. Res. Lett., 29, 1813, doi:10. 1029/2001GL014440, 2002.

Peter, T., Marcolli, C., Spichtinger, P., Corti, T., Baker, M. B., and Koop, T.: When Dry Air Is Too Humid, Science, 314, 13991402, doi:10.1126/science.1135199, 2006.

Read, W. G., Waters, J. W., Flower, D. A., Froidevaux, L., Jarnot, R. F., Hartmann, D. L., Harwood, R. S., and Rood, R. B.: UpperTropospheric Water Vapor from UARS MLS, B. Am. Meteorol. Soc., 76, 2381-2389, 1995.

Read, W. G., Waters, J. W., Wu, D. L., Stone, E. M., Shippony, Z., Smedley, A. C., Smallcomb, C. C., Oltmans, S., Kley, D., Smit, H. G. J., Mergenthaler, J. L., and Karki, M. K.: UARS Microwave Limb Sounder upper tropospheric humidity measurement: Method and validation, J. Geophys. Res., 106, $32207-$ 32 258, 2001.

Read, W. G., Lambert, A., Bacmeister, J., Cofield, R. E., Christensen, L. E., Cuddy, D. T., Daffer, W. H., Drouin, B. J., Fetzer, E., Froidevaux, L., Fuller, R., Herman, R., Jarnot, R. F., Jiang, J. H., Jiang, Y. B., Kelly, K., Knosp, B. W., Pumphrey, H. C., Rosenlof, K. H., Sabounchi, X., Santee, M. L., Schwartz, M. J., Snyder, W. V., Stek, P. C., Su, H., Takacs, L. L., Thurstans, R. P., Vömel, H., Wagner, P. A., Waters, J. W., Webster, C. R., Weinstock, E. M., and Wu, D. L.: Aura Microwave Limb Sounder upper tropospheric and lower stratospheric $\mathrm{H}_{2} \mathrm{O}$ and relative humidity with respect to ice validation, J. Geophys. Res., 112,
D24S35, doi:10.1029/2007JD008752, 2007.

Ridolfi, M., Carli, B., Carlotti, M., Clarmann, T. V., Dinelli, B. M., Dudhia, A., Flaud, J.-M., Höpfner, M., Morris, P. E., Raspollini, P., Stiller, G., and Wells, R. J.: Optimized forward model and retrieval scheme for MIPAS near-real-time data processing, Appl. Optics, 39, 1323-1340, 2000.

Sassi, F., Salby, M., and Read, W. G.: Relationship between upper tropospheric humidity and deep convection, J. Geophys. Res., 106, 17 133-17 146, 2001.

Sherwood, S. C. and Dessler, A. E.: On the control of stratospheric humidity, Geophys. Res. Lett., 27, 2513-2516, 2000.

Soden, B. J.: The diurnal cycle of convection, clouds, and water vapor in the tropical upper troposphere, Geophys. Res. Lett., 27, 2173-2176, 2000.

Soden, B. J. and Bretherton, F. P.: Interpolation of TOVS water vapor radiances in terms of layer-average relative humidities: Method and climatology for the upper, middle and lower troposphere, J. Geophys. Res., 101, 9333-9343, 1996.

Soden, B. J., Turner, D. D., Lesht, B. M., and Miloshevich, L. M.: An analysis of satellite, radiosonde, and lidar observations of upper tropospheric water vapor from the Atmospheric Radiation Measurement Program, J. Geophys. Res., 109, D04105, doi:10.1029/2003JD003828, 2004.

Sonntag, D.: Advancements in the field of hygrometry, Meteorol. Z., 3, 51-66, 1994.

Spichtinger, P., Gierens, K., and Read, W.: The global distribution of ice-supersaturated regions as seen by the Microwave Limb Sounder, Q. J. Roy. Meteor. Soc., 129, 3391-3410, doi: 10.1256/qj.02.141, 2003.

Spichtinger, P., Gierens, K., Smit, H. G. J., Ovarlez, J., and Gayet, J.-F.: On the distribution of relative humidity in cirrus clouds, Atmos. Chem. Phys., 4, 639-647, 2004, http://www.atmos-chem-phys.net/4/639/2004/.

Tian, B., Soden, B. J., and Wu, X.: Diurnal cycle of convection, clouds, and water vapor in the tropical upper tropopsphere: Satellites versus a general circulation model, J. Geophys. Res., 109, D10101, doi:10.1029/2003JD004117, 2004.

Waters, J. W., Froidevaux, L., Harwood, R. S., Jarnot, R. F., Pickett, H. M., Read, W. G., Siegel, P. H., Cofield, R. E., Filipiak, M. J., Flower, D. A., Holden, J. R., Lau, G. K., Livesey, N. J., Manney, G. L., Pumphrey, H. C., Santee, M. L., Wu, D. L., Cuddy, D. T., Lay, R. R., Loo, M. S., Perun, V. S., Schwartz, M. J., Stek, P. C., Thurstans, R. P., Boyles, M. A., Chandra, K. M., Chavez, M. C., Chen, G.-S., Chudasama, B., Dodge, R., Fuller, R. A., Girard, M. A., Jiang, J. H., Jiang, Y., Knosp, B. W., LaBelle, R. C., Lam, J. C., Lee, K. A., Miller, D., Oswald, J. E., Patel, N. C., Pukala, D. M., Quintero, O., Scaff, D. M., Snyder, W. V., Tope, M. C., Wagner, P. A., and Walch, M. J.: The Earth Observing System Microwave Limb Sounder (EOS MLS) on the Aura Satellite, IEEE Trans. Geosci. Rem. Sens., 44, 1075-1092, doi:10.1109/TGRS.2006.873771, 2006.

Zhang, C., Mapes, B. E., and Soden, B. J.: Bimodality in tropical water vapour, Q. J. Roy. Meteor. Soc., 129, 2847-2866, doi:10. 1256/qj.02.166, 2003. 